\title{
O PAPEL DO DISCURSO FILOSÓFICO NA INTERPRETAÇÃO RELIGIOSA: NOTAS SOBRE A LINGUAGEM NO FASL-AL MAQAL DE AVERRÓIS.
}

\author{
Arthur Klik de Lima \\ Universidade Federal de Lavras
}

\begin{abstract}
RESUMO: No Discurso Decisivo, Averróis analisa os três modos que considera como válidos para o assentimento religioso, considerando cada um destes como atrelados a um modo discursivo; demonstrativo, dialético e retórico. A partir disso, afirma a demonstração como o modo mais excelente e, com isso, fazendo necessária a análise da validade que as outras vias possuem, visto que isso será determinante para que se estabeleçam as possibilidades interpretativas do texto sagrado. Averróis se utiliza deste expediente para desenvolver sua tese a respeito da harmonia entre filosofia e revelação, ponto central da obra, o que torna fundamental compreender a relação intrínseca que as formas discursivas deverão manter, evitando a contradição entre o filosófico e o religioso, que só ocorrerá quando os termos não forem corretamente organizados. Em outras palavras, a possível contradição ocorrerá quando estas modalidades interpretativas estabelecem alguma forma de concorrência com a demonstração, premissa que contribui para o posicionamento dos praticantes da ciência demonstrativa como os legítimos intérpretes do texto sagrado.
\end{abstract}

Palavras-chaves: Averróis, discurso, demonstração, razão, revelação.

ABSTRACT: In his Decisive Treatise, Averroes analyzes the three valid modes for religious assent, each of them considered as being linked to a discursive mode; demonstrative, dialectical and rhetorical. From this, he affirms the demonstrative way as the most excellent, and thereby making necessary the analysis of the validity that the other ways have, since this will be decisive for the establishment of the interpretative possibilities of the Divine Law. Averroes uses this discussion to develop his thesis about the harmony between philosophy and revelation, central point of the Decisive Treatise, which makes our matter fundamental to understand the intrinsic relation that the discursive forms must maintain, avoiding the contradiction between the philosophical and the religious, which only occurs when the terms are not correctly organized. In other words, the apparent contradiction between them will occur when these interpretative modalities establish in some ways a competition with demonstration. That is also a premise that contributes to the positioning of demonstrative science practitioners as the legitimate interpreters of the sacred text.

KEYWORDS: Averroes, speech, demonstration, razão, revelation. 


\section{O problema da interpretação do texto sagrado}

Averróis apresentou à história da filosofia um pensamento singular, tradicionalmente conhecido entre os cristãos como o "problema da unidade do intelecto", e sua ampla discussão no século XIII. No entanto, parte fundamental de seu trabalho intelectual não foi conhecida por este período histórico, parte esta que foi dedicada a analisar as questões político-religiosas de seu tempo ${ }^{1}$. Destaca-se neste contexto a seguinte obra: ou Discurso Decisivo sobre o acordo entre a filosofia e a religião ${ }^{2}$, cujos aspectos da polêmica a respeito de sua tese serão explorados neste artigo. Este título já nos antecipa o caráter polêmico, um acordo entre a filosofia e a religião. Trata-se de uma fatwa, um pequeno texto de natureza quase epistolar, de caráter jurídico, onde o autor tradicionalmente divulga publicamente uma espécie de parecer a respeito de uma ou mais questões. Neste caso, um conjunto de questões que envolvem a relação entre a filosofia e a religião no contexto social de Averróis ${ }^{3}$.

Primeiramente, é necessário realizar uma análise a respeito da maneira por meio da qual ele estabelece a relação entre seu pensamento, cuja inclinação aristotélica é evidente, e o contexto da religião islâmica no qual está inserido. A partir disso, é importante destacar que a relação entre filosofia e a Lei revelada nunca foi território pacífico na tradição da filosofia árabe medieval. Podemos afirmar que Averróis já se encontra, nesta matéria, diante de uma longa discussão sobre esta relação. A pergunta, por excelência, parece se voltar para o estatuto que a investigação da verdade possui em relação a verdade revelada, observando em que medida, a investigação filosófica é autorizada pela lei religiosa e, sendo algo autorizado pela Lei, trata-se de uma recomendação ou de uma obrigação imposta a todo aquele que crê?

A partir disso, é possível considerar o estabelecimento de uma oposição entre as duas formas supracitadas, que conduziria os homens a uma duplicidade da verdade. A

\footnotetext{
${ }^{1}$ Averróis pertence a uma longa linhagem de juristas da Andaluzia. Cf. (URVOY, 1998, pg. 15)

2 "KitabFasl al-maqalwataqrirmabaynash-shari'awal-hikma min al-ittisal". Cuja tradução mais aproximada é: "O livro do discurso decisivo onde se estabelece a conexão existente entre a revelação e a filosofia". Neste artigo, utilizaremos a tradução francesa de Marc Geoffroy. (AVERROES, 1996)

${ }^{3}$ Emitir esse tipo de parecer juridico é uma das tarefas do "juiz dos juízes", cargo ocupado por Averróis na mesquita de Córdoba.
} 
resposta de Averróis parece estar profundamente comprometida em dirimir essa "duplicidade", pois considera fundamental que a especulação filosófica encontre sua relação na vida prática, em como as ações humanas podem ter, enquanto objeto de estudo, função determinante na compreensão da lei revelada. ${ }^{4}$

A filosofia grega parece não ter encontrado entre os árabes a mesma possibilidade de aproximação que encontrou em solo cristão. Isto se considerarmos as proporcionais diferenças históricas e culturais, pode-se afirmar que, em sua relação com o cristianismo, a filosofia experimentou progressiva "institucionalização". Em outras palavras, ela foi progressivamente incorporada até o que se pode considerar como uma quase assimilação. No que tange a falsafa, esta relação não parece ter se constituído do mesmo modo, e a filosofia grega restou como um elemento cuja apropriação foi criticada em praticamente todos os períodos de contato. A oposição aparente entre as "duas verdades" foi uma constante nas discussões sobre diversos aspectos religiosos do islã. Neste sentido, vale ressaltar que a aproximação entre filosofia e lei revelada será uma constante no trabalho intelectual de Averróis, sobretudo, na elaboração do "discurso decisivo", pois é no estabelecimento desta relação que se encontrará o futuro da filosofia tal qual ele a concebe ${ }^{5}$.

A diferença entre os comentários de Averróis e suas obras originais é apenas certo aprofundamento do foco de análise em uma questão específica. Por exemplo, ao comentar as obras de Aristóteles, o que parece estar em jogo é a investigação da natureza, cujo sentido é conhecer os processos que orientam todos os seres naturais. Assim, ainda que a investigação aristotélica procure dar conta de todo um expediente de questões fundamentais sobre o Ser, elas não consideram, por razões obvias, a dimensão religiosa que os judeus, árabes e cristãos, se ocuparão longamente em esclarecer. Por isso, Averróis procura demonstrar que a relação entre estes dois aspectos, a investigação da natureza e a religião, constituem etapas de um processo que orienta os seres naturais,

\footnotetext{
${ }^{4}$ Averróis nasce em um ambiente politicamente tenso, marcado por diversas revoltas. Sua vida intelectual é também marcada pela defesa de certas posições religiosas, como a que estamos analisando neste artigo. Cf. URVOY, 1998, pg. 33.

${ }^{5} \mathrm{O}$ artigo de Richard Taylor (2000), "Truth does not Contradict Truth: Averroes and the Unity of Truth.", explora amplamente a questão. Cf. também, (OZCOIDI, 2001, pg. 62).
} 
que pode ser compreendido pela razão, pois também está em completa harmonia e continuidade com a revelação. É por isso que a legitimidade da filosofia também trata de uma investigação no âmbito jurídico, pois o que se procura encontrar, neste caso, é o arcabouço jurídico que, segundo Averróis, também é manifesto na lei revelada, e que corrobora a investigação dos entes naturais. ${ }^{6}$

A lei religiosa $\left(\right.$ shari $\left.{ }^{7} a^{7}\right)$ pode ser compreendida com um sinônimo para a prática religiosa, e pode ser entendida como uma guia mestra para as ações individuais, que tem seu sentido prático completamente atrelado ao da aplicação da revelação. Em outras palavras, a prática religiosa que o fiel deve observar é rigorosamente a aplicação da lei revelada. Contudo, é possível afirmar que esta formulação parece simples por demais, pois a grande questão de fundo consiste em saber como aplicar a Lei nos casos em que o texto revelado não é compreendido pelos homens, onde a interpretação parece guardar os maiores problemas, sendo uma das fontes para o questionamento da legitimidade da filosofia como guia de interpretação do texto revelado.

Obviamente, o debate entre fé e razão também foi bastante explorado em terras cristãs, onde adquire múltiplas acepções. Entre a falsafa, é possível afirmar que o debate é centralizado na validade do discurso filosófico frente ao texto revelado e em praticamente todas as questões decorrentes disso, como a interpretação, o uso das metáforas; e mesmo o estatuto da dialética e da retórica como meios válidos para análise. Muito dos esforços dos trabalhos originais de Averróis vão ao sentido de também combater o que se pode entender como um movimento antifilosófico, que procura deslegitimar a filosofia como meio válido de análise por estar em conflito com a revelação ${ }^{8}$. Assim, faz-se necessário analisar como Averróis soluciona este conflito.

\footnotetext{
${ }^{6}$ Cf. URVOY, 1998, pg.148.

7 Resumidamente, é possível afirmar que a Shari'a constitui o corpo de obrigações que o fiel deve cumprir, sendo responsável pela condução dos aspectos públicos e particulares da vida dos muçulmanos. Qualquer discussão sobre os aspectos fundamentais da religião constitui impacto direto na aplicação da Shari'a.

${ }^{8}$ Neste contexto, isto é manifesto pelo discurso dos chamados teólogos asharitas, cuja personificação se dá, sobretudo, na figura de Al-Ghazali e seu tratado A incoerência dos filósofos.
} 


\section{O filósofo e a shari' $a^{9}$}

Podemos dizer que o Fasl al-maqalé dedicado a analisar os critérios que podem garantir que a prática da investigação demonstrativa, possa galgar com certa autonomia algum nível de conhecimento a respeito da revelação. No que diz respeito a seu conhecimento, é fundamental que a revelação seja de acesso garantido a todos os homens, o que torna a tarefa da interpretação um tanto quanto mais complexa. Como conciliar a gratuidade da revelação ao conhecimento filosófico que demanda longos esforços e, por isso, se recolhe a poucos indivíduos?

De início é importante considerar que um dos pontos fundamentais é sustentar que a revelação afirma que a capacidade racional não pode ser desconsiderada como acesso a revelação, pois é necessário que se estabeleça uma espécie de "critério de igualdade" neste acesso. Os homens não seriam dotados de um complexo aparato intelectivo apenas para que seu uso fosse interditado por Deus ${ }^{10}$. Ao contrário, ele considera que a possibilidade de assentimento religioso está diretamente vinculada a esta capacidade. Tal consideração também tem lugar quando se observa uma espécie de "prova dos efeitos" chamada por Averróis de "prova do artesão"11, que pode ser resumida no argumento da percepção da causa primeira, que é feita por meio da observação da causalidade natural, cuja conclusão afirma que, por trás do produto da arte, há sempre um artesão.

Apontar a filosofia como um "caminho para o criador" foi motivo de controvérsia desde os primórdios do contato da filosofia grega com as religiões monoteístas. E a questão da interpretação está relacionada diretamente ao modo como o conhecimento racional ou a ciência serão concebidos a partir deste contato. A posição de Averróis a

\footnotetext{
${ }^{9}$ A discussão entabulada por Averróis sobre o papel do filósofo em sua sociedade está diretamente relacionada a este termo. Por definição, a Shari'a deve manifestar o mandamento divino, constituindo a prática orientada pelo conteúdo da revelação. Os múltiplos debates que surgiram a esse respeito são fruto de tentativas de compreender a prática de se deveria seguir a partir de um determinado mandamento contido na revelação. Já nos primeiros parágrafos do texto, Averróis recorre a uma classificação das modalidades de ações possíveis e suas adequadas recompensas, e o quadro formado a partir das relações entre elas já nos revela algo da sua compreensão da aplicação da Shari'a. (AVERROES, 1996, pg.103). Cf. também: TAYLOR, 2012, pg. 287.

${ }^{10}$ Cf. URVOY, 1998, pg. 152.

${ }^{11}$ Cf. AVERROES, 1996, pg. 103.
} 
esse respeito é um tanto quanto contundente, pois considera que o exercício demonstrativo não só é autorizado, mas constrangido a interpretar o texto sagrado. Em outras palavras, todo aquele que possui a capacidade, e encontra os meios para estudar a ciência demonstrativa, não só pode como deve fazer isso.

A revelação deve acessar a todos os homens, e mesmo aqueles que se voltam para a ciência demonstrativa não podem se considerar "livres" desta regra, pois o conhecimento obtido por esta via serve ao mesmo propósito que o da revelação. Autorizar a filosofia é também permitir que o propósito da revelação se cumpra, e que cada homem possa assentir ao Islã de maneira proporcional a suas capacidades. Quanto a sua proibição:

[...] equivale a proibir o sedento de beber água fresca e agradável até que morra de sede, pelo motivo de que outros que dela beberam engasgaram-se e morreram. Na verdade, a morte que resulta do engasgamento que a água possa produzir é de caráter acidental, enquanto a que decorre da sede é de caráter essencial e necessário. ${ }^{12}$

Para Averróis, este é o único caminho para que o sentido da revelação se complete, pois, ao indivíduo que assente ao islã, duas questões devem ser observadas, a clareza na compreensão da revelação e a liberdade no assentimento. E estas só podem se concretizar quando este homem for capaz de compreender a revelação por meio de suas capacidades, podendo assimilá-la e agir livremente do sentido de confirmar sua adesão religiosa.

A liberdade do assentimento será pautada na diversidade que diz respeito a natureza dos homens, princípio que determina o modo de agir que é próprio de cada uma destas, e que também estabelece a propriedade e o uso adequado de cada uma das modalidades lógicas e discursivas que acompanham cada uma das formas de assentimento. Há homens que só poderão assentir a religião se percorrerem o caminho da ciência demonstrativa, enquanto outros poderão confirmar seu assentimento religioso por outras vias. O que importa é que a revelação consiga alcançar a todos estes homens.

\footnotetext{
${ }^{12}$ AVERROES, 1996, pg. 115-116.
} 
Tal perspectiva visivelmente assegura o papel legitimo da filosofia, neste caso, da lógica aristotélica como método ideal de pratica da racionalidade, onde a demonstração ocupará este papel central. Apenas os homens que se debruçam sobre a ciência demonstrativa estão verdadeiramente capacitados no conhecimento do livro sagrado, e proibir que tais homens possam acessar demonstrativamente o texto é um desrespeito ao mandamento corânico.

\footnotetext{
Mas proibir totalmente [os livros de demonstração] significa barrar o acesso a alguma coisa que Revelação chama a praticar; por que é cometer uma injustiça a classe mais perfeita dos humanos, e a classe mais perfeita dos seres. Pois é um bem que esta (a Lei) seja conhecida tal como ela é por aqueles que estão dispostos a conhecê-la tal como ela é: os homens da classe mais perfeita. ${ }^{13}$
}

Segundo Averróis, os homens que possuem a capacidade demonstrativa devem ser incentivados a desenvolver esta capacidade, pois a consideração de que o discurso filosoficamente orientado está em contradição com a revelação, não é mais que um erro fundamentado por fatores externos, que introduzem acidentalidades a essas leituras, basicamente em função de uma má aplicação dos silogismos ou do tratamento das premissas. O erro não estaria contido na revelação ou no discurso filosófico, visto que a natureza de ambos está diretamente associada à verdade, e o caráter acidental dos erros é fruto da aproximação destas formas investigativas com as capacidades humanas, que conduzem a investigação por meio da aplicação das operações lógicas. O erro consiste exatamente na flexibilidade das operações intelectuais de composição e divisão que são próprias dos homens, mas que, quando não possuem o conhecimento das ciências demonstrativas, acabam incidindo nas armadilhas que o mau uso da lógica pode induzir.

Assim, também é necessário ressaltar que adotar uma defesa tão significativa da demonstração trará para Averróis uma série de problemas, entre eles a desconfiança de outras linhas de pensamento que se fundamentam na leitura literal do Corão. A base da acusação feita ao modo de leitura proposto por Averróis se fundamenta em uma relação de submissão que seria estabelecida pelo texto sagrado em relação à filosofia, caso a demonstração fosse aplicada ao texto sagrado. Em outras palavras, o sentido da

\footnotetext{
${ }^{13}$ AVERROES, 1996, pg. 149. Cf. também OZCOIDI, 2001, pg. 67.
} 
revelação seria supostamente pervertido pela interpretação, e "adaptado" aos interesses dos leitores da filosofia para que se torne mais próximo de seus interesses. A tarefa da razão é encontrar os elementos para a submissão ao Corão e não a de submetê-lo a doutrinas pretensiosamente racionais, tais leituras acusam Averróis de praticar uma “inovação condenável” (bid'a) ${ }^{14}$. Tal termo expressa a introdução de algum elemento novo na doutrina corânica, mas sem que este conteúdo encontre sua validade na lei religiosa, ou mesmo nas coletâneas da tradição, o que representaria uma modificação essencial no corpo da doutrina, que se corromperia em nome de algo externo. Isso é considerado um crime grave cometido contra a lei religiosa.

\section{Assentimento e filosofia}

Neste sentido, faz-se necessário examinar como Averróis define esta relação entre filosofia e assentimento religioso, visto que não parece encontrar as mesmas consequências danosas que seus interlocutores enxergam em sua posição. O Discurso Decisivo já se inicia definindo a atividade filosófica como uma análise realizada através da demonstração, direcionada para os seres existentes, pois o conhecimento na natureza é também um reflexo do Criador ${ }^{15}$. Esta definição parece inclinar o propósito da filosofia para uma espécie de prova da existência de Deus, que considera a prática racional como uma orientação natural do homem para conhecimento de seu princípio. Pois, de fato, é na medida em que conhecemos sua construção é que os seres constituem uma prova da existência do Artesão [... ${ }^{16}$.

A engenhosidade do argumento de Averróis se apoia no sentido de que é a própria revelação quem faz o convite para a investigação dos seres naturais, e o sentido último

\footnotetext{
${ }^{14}$ É necessário justificar que o uso do silogismo demonstrativo pode ser visto no contexto religioso, como algo que fere a ortodoxia da lei religiosa, apoiando-se na hipótese de que se trata de uma inovação, algo que não tem o seu uso previsto nem no Alcorão quanto na tradição (hadits). Averróis afirma que o silogismo jurídico também não estava assinalado nos primórdios do Islã, sendo algo que foi descoberto posteriormente e tornou-se um estudo obrigatório a todo legislador.

${ }^{15}$ No entanto, nossa compreensão desta premissa se aproxima com a deHourani em sua tradução do Fasl al-Maqal, que não a concebe como necessariamente relacionada ao estudo da filosofia. Cf. HOURANI, 2012, pg. 82-85.

${ }^{16}$ AVERROES, 1996, pg. 103.
} 
disto é que o criador se revela naturalmente em suas obras, e os homens naturalmente dotados da capacidade necessária para conhecer esta marca do criador em todas as coisas. A natureza é um dos modos pelos quais o criador se revela a estes, e isso basta para que a filosofia se sustente como uma investigação válida, pois nada seria mais legítimo ao homem do que usar a capacidade mais nobre que lhe foi doada pelo criador no sentido de procurar conhecê-lo. Impedir os homens de realizar tal propósito é que constitui falta grave contra a lei religiosa.

\begin{abstract}
E se a Lei divina é a verdade, e se ela convida a praticar o exame racional que leva ao conhecimento da verdade, então, certamente, nós, da comunidade dos muçulmanos estamos convencidos de que a especulação demonstrativa não pode conduzir a conclusões diferentes daquelas contidas na Lei, já que a verdade não contraria a verdade, mas concorda com ela e dá testemunho em favor dela. ${ }^{17}$
\end{abstract}

Este sentido de análise filosófica extrapola o de uma ciência que analisa os seres naturais e suas relações, acrescida da tarefa de ser uma fonte de fundamentação para o assentimento religioso. Segundo Averróis, há homens que só poderão assentir verdadeiramente se alcançarem esta certeza através da demonstração. Por isso é natural que se permita aos homens a filosofia.

\begin{abstract}
Se o ato de filosofar consiste na reflexão sobre os seres existentes e na consideração destes, do ponto de vista de que constituem a prova da existência do Artesão, quer dizer: enquanto são artefatos - pois certamente é na medida em que se conhece sua construção que os constituem uma prova da existência do Artesão; e se a Lei religiosa recomenda a reflexão sobre os seres existentes e mesmo estimula para isso, então é evidente que a atividade designada por esse nome é considerada pela Lei religiosa seja como obrigatória, seja como recomendada. ${ }^{18}$
\end{abstract}

É importante considerar como muita atenção qual é o sentido desta obrigação ou recomendação que encerra a passagem supracitada. Postular a demonstração como "mais um caminho" para o assentimento parece ser exatamente o que gera o problema do qual Averróis quer se esquivar, pois considerar como válida a premissa de que a lei sagrada possui mais de uma via de acesso é relativizar o papel da revelação, o que também parece contradizer tudo aquilo que foi desenvolvido até agora. A tese de

${ }^{17}$ AVERROES, 1996, pg. 119.

${ }^{18}$ AVERROES, 1996, pg. 103-105. 
Averróis segue no sentido de superar essa aparente contradição, pois assumir diferenças nos níveis de assentimento parece considerar diferenças no que tange a natureza dos homens. O que também obrigará a considerá-las de maneira hierarquizada, e distinguir os homens entre as formas de assentimento, mas sem distingui-los enquanto espécie. $\mathrm{O}$ sentido dado por Averróis para esta "diferença de natureza" parece estar direcionada para o grau de atualização em que a capacidade racional se encontra, e isso determinaria a "via de acesso" a lei revelada e, consequentemente, a clareza em sua compreensão. $O$ que parece assumir que a inclinação natural de todos os homens para Deus signifique que todos eles buscam o conhecimento de deus. A variação do acesso diz respeito ao modo em que essa busca é realizada.

Por isso, não se tratará apenas de legitimar a prática filosófica, mas também de apresentá-la como a mais plena manifestação da razão humana, e a mais adequada fonte de interpretação da religião. Se a capacidade racional é autorizada e incentivada pelo Corão, a melhor forma de utilizar a razão também será a melhor forma de acesso ao conteúdo da revelação.

O argumento de Averróis para o uso das ciências da antiguidade considera que é fundamental para qualquer investigação em que se conheça a história daquilo que está sendo investigado, $[. .$.$] é preciso que tomemos em mãos seus livros, a fim de verificar$ tudo o que disseram. Se tudo for justo, nós o receberemos deles; e se for encontrado alguma coisa que não o seja, nós o mostraremos ${ }^{19}$. Orientado por uma inclinação que muito se assemelha a de $\mathrm{Al}-\mathrm{Kindi}^{20}$, nos primórdios da recepção da antiguidade pelos árabes, ele considera que a ciência é tarefa da humanidade, e seu avanço deve respeitar aquilo que historicamente foi sedimentado e que serve como impulso para as futuras gerações, que darão continuidade a investigação.

\footnotetext{
${ }^{19}$ AVERROES, 1996, pg. 111.

20 Uma expressão mais famosa também pode ser encontrada ainda nos primórdios da recepção da filosofia grega por Al-Kindi, onde a inspiração do argumento de Averróis parece seguir a mesma inclinação. Em seu texto A filosofia Primeira, Al-Kindi analisa diversos aspectos essenciais da investigação filosófica, dentre eles, a sua adequação ao contexto islâmico. Ao questionar a validade do uso das fontes oriundas da antiguidade grega, o argumento do pioneiro da falsafa se dará no sentido de justificar a presença dos antigos como uma tarefa natural a todo aquele que se compromete com a investigação da verdade. Cf. Al-KINDI, 2014 e GUERRERO, 1986.
} 
Naturalmente, embora seja a mais alta manifestação do exercício da razão, a filosofia não está livre de equívocos. Como foi dito, por se tratar de uma ciência produzida pelos homens, estes certamente cometerão erros ao lidar com ela. No entanto, a atribuição deste erro deve ser destinada aos homens, e não a pratica da ciência demonstrativa, que em si mesma não é boa ou má, mas que pode causar o bem ou o mal, conforme o uso que lhe for dado. Possibilidades de erro da qual também padeceriam as variadas ciências que fazem uso das diversas modalidades de silogismo, onde basta apenas introduzir premissas inadequadamente, para que seu conteúdo seja comprometido.

\section{Sobre a interpretação}

Dizer que há modos de assentimento destinados a certos homens é classificá-los, e atribuir classes a eles é considerar que há modos distintos de acesso à revelação. A distinção no assentimento estará pautada nos modos como os homens são capazes de acessar e compreender a verdade da mensagem contida na lei sagrada. Como vimos, esta diferenciação parece não comprometer o sentido unívoco da perfeição contida na revelação, pois ela deve servir indistintamente a todos os homens. Em outras palavras, é necessário que todos estes, sem distinção, sejam capazes de assentir por meio da revelação. Assim, como nossa lei divina convoca os homens por meio destes três caminhos, deve ser generalizado o assentimento de toda a gente $[\ldots]^{21}$

Explorar o sentido desta distinção vai aprofundar a análise das formas discursivas que estão envolvidas nesta classificação. O que é um dos pontos fundamentais onde a questão da interpretação do livro sagrado será desenvolvida, pois cada forma de assentimento será associada a uma forma discursiva. Neste sentido, os três modos de assentimento se distribuem pela retórica, dialética e demonstração, que são os três modos de válidos elencados por Averróis. Os homens que são conduzidos ao assentimento pela retórica representam o menor grau de conhecimento; homens simples cujo apelo emocional que pode ser manifesto na retórica os leva ao assentimento. Estes

\footnotetext{
${ }^{21}$ AVERRÓIS, 1996, pg. 117-118.
} 
homens possuem um conhecimento bastante superficial da revelação e praticamente não conseguem escapar do uso das metáforas e alegorias. $\mathrm{O}$ assentimento alcançado por premissas dialéticas já conduzem os homens a um expediente de conclusões intermediárias, prováveis, que as aproxima de uma esfera investigativa, mas que ainda carregam consigo a impossibilidade da certeza que é própria da análise demonstrativa. Esta última, a forma considerada por Averróis como a maneira mais excelente de conduzir um indivíduo ao assentimento, por apresentar conclusivamente os julgamentos necessários para aproximar os homens da verdade contida na revelação. Isto pode ser visto nas palavras do comentador:

De fato, existe diversificação das naturezas humanas no que toca ao assentimento: há os que assentem pela demonstração; outros que assentem por meio dos argumentos dialéticos, semelhante ao assentimento da demonstração, pois suas naturezas não os dispõem para mais do que isso; e há os que assentem pelos argumentos retóricos, assentimento semelhante ao dos que assentem à demonstração por argumentos demonstrativos. ${ }^{22}$

Averróis aponta que o grande problema reside em uma classe de "teólogos" ${ }^{23}$, supostos conhecedores da lei revelada que, por desconhecerem a demonstração, usam seu conhecimento, para o alcance de suas "certezas". Para ele, o suposto conflito entre a filosofia e a lei religiosa diz respeito ao fato de que estes homens não conhecem adequadamente as operações da ciência demonstrativa e, com isso, suas respostas são corrompidas por premissas distorcidas. Para Averróis, a base dialética na qual se fundamentam as afirmações destes teólogos é o que guia suas conclusões ao estabelecimento das contradições. Estes homens não compreenderiam seu papel dentro da estrutura do conhecimento, pretensamente se declarando como estudiosos e conhecedores da lei revelada. Introduzir limitações ao acesso à revelação serve para justificar seus argumentos de autoridade. Estes homens se colocariam entre o texto e a fé, condicionando o assentimento a uma leitura mais particular, que afirmaria a responsabilidade sobre a verdadeira interpretação do texto sagrado.

\footnotetext{
22 AVERRÓIS, 1996, pg. 116.

${ }^{23}$ Este é o termo ocidental que é geralmente utilizado para se referir a estes homens contra os quais Averróis se pronuncia, os mutakallimun, os homens conhecedores da Lei. No entanto, é importante ressaltar que este é um termo multifacetado, pois seu uso diverge conforme o contexto no qual está sendo utilizado.
} 
Para Averróis, qualquer que seja a forma de assentimento, esta será considerada racional, pois o exercício religioso é também uma prática da razão. Lembramos que o objetivo último das ciências é um reconhecimento da existência do criador por meio de sua obra, esta, como manifestação da verdade, deve ser acessível e alvo de compreensão por todos os homens. A força do erro reside na tentativa de estabelecer limites à mensagem contida na revelação. Trata-se aqui de uma das considerações ousadas que Averróis faz ao relacionar a Lei com a filosofia, pois considera que o texto sagrado possui "camadas" que revelam seu sentido essencial, que não excluem aqueles que não são capazes de compreender este sentido último, que poderão seguir a mensagem em suas camadas mais superficiais.

O cuidado em determinar quem está ou não autorizado a interpretar o texto sagrado, parece ter em mente que a contradição interpretativa surge quando há conflito entre a literalidade da mensagem e seu sentido interpretado. Neste caso, o problema deve residir na interpretação, pois aquele que é capaz de captar o sentido oculto do texto sagrado, também será capaz de observar sua harmonia com seu sentido literal, e dissolver o conflito. O ponto em questão diz respeito ao fato de que os caminhos do assentimento (retórico, dialético e demonstrativo), não podem representar entre si uma contradição, devendo manifestar uma continuidade observável por aquele capaz de acessar as três instâncias investigativas. Com seu desenrolar último na demonstração, os argumentos dialéticos e retóricos têm sua contribuição na contemplação da gratuidade do conteúdo da revelação, garantindo que todos os homens tenham acesso a esse conhecimento. ${ }^{24}$

Neste sentido, o Corão pode ser entendido como o texto que fornece tanto um sentido investigativo para aquele que busca se aproximar da verdade por meio de uma investigação, quanto contém o conjunto de regras que orienta a vida daqueles que estão satisfeitos com esta orientação da revelação. Os sinais divinos estariam expressos nas

\footnotetext{
${ }^{24}$ Retórica e dialética se assemelhem mais a opinião do que ao conhecimento, uma boa opinião pode ser o principio para a aquisição deste último, uma alusão muito semelhante ao que pode ser observado na retórica de Aristóteles. Cf. BUTTERWORTH, 1972, pg. 895.
} 
orientações que guiariam a vida cotidiana e que se aplicariam a todos os homens. ${ }^{25}$ Apenas uma elite intelectual que buscaria seu sentido oculto, esta ultima, constituída por poucos indivíduos capacitados a realizar a investigação demonstrativa.

Para Averróis, não é possível que exista contradição entre o discurso demonstrativo e o texto da Lei revelada. A lei deve atender a todos os homens igualmente, mesmo os investigadores da verdade vão encontrar suas respostas por meio dela, fundamentando seu assentimento deste modo. Averróis usa como exemplo a questão da vida futura, de grande obscuridade mesmo para aqueles que investigam por meio da demonstração. Neste caso, o uso das imagens lhe parece lícito, pois entende que os homens que não estão preparados para receber a ciência não serão capazes de compreender nada que não possua relação direta com a formação das imagens sensíveis, visto que mal ultrapassam este registro. Assim, o filósofo pode utilizar de metáforas para esclarecer estes homens, por exemplo, atribuir características corpóreas a Deus. Esta "elite intelectual" afirmada por Averróis, ao conquistarem uma compreensão mais profunda do texto sagrado, tornam-se responsáveis não apenas por si, mas também se comprometem a guiar os indivíduos que não são capazes de alcançar esta compreensão por si. Isto se torna mandatório a estes homens, a capacidade de interpretar está atrelada à obrigação de orientar, tendo alcançado o assentimento pela demonstração, a mais alta manifestação da razão acaba por "imunizar" o indivíduo para as outras formas de assentimento. Para a elite, entretanto, é um dever interpretar esse tipo de argumento, $e$ o dever do povo é prender-se no sentido óbvio. ${ }^{26}$

No entanto, este sentido não é menos problemático, pois o estabelecimento de "camadas" na compreensão do texto revelado também será responsável pela criação de certo regime de exclusividade para o teor de certas orientações. Estas seriam destinadas apenas aos homens capacitados demonstrativamente, que não deveriam revelar este

\footnotetext{
${ }^{25}$ Temos em mente a seguinte passagem do texto: «É preciso que saibamos que o propósito da Lei é exatamente: ensinar a ciência verdadeira e a prática verdadeira. A ciência verdadeira é o conhecimento de Deus - Bendito e exaltado seja - e do conjunto dos seres existentes tal qual são - em especial dos mais honrados entre eles - e o conhecimento da bem-aventurança e dos tormentos da outra vida. E a prática verdadeira consiste no cumprimento de atos que garantam a bem-aventurança e no evitar atos que levem aos tormentos. O conhecimento destes atos chama-se ciência prática. » AVERRÓIS, 1996. pg. 149.

${ }^{26}$ AVERRÓIS, 1996, pg. 153. Cf. também URVOY, 1998, pg. 153.
} 
sentido aos homens comuns, já que estes seriam absolutamente incapazes de compreender tais orientações. Averróis também esclarece que o conflito entre a lei e a interpretação não é algo completamente impossível, mas que todo erro deve ser sempre imputado na interpretação. Em outras palavras, quando se fizer necessário decidir entre o sentido literal e o interpretativo, é necessário que se volte para o sentido literal, pois a contradição se encontrará na interpretação. A passagem que ilustra isso:

Se interpretações da Lei Religiosa estiverem em conflito com proposições demonstrativas, o primeiro deve dar lugar ao segundo, não por que a verdade da Lei Religiosa tem sido contradita, mas, por que a verdade da interpretação da lei religiosa tem sido contradita. ${ }^{27}$

E não importa qual seja a via, o sentido da revelação se direciona para o verdadeiro conhecimento e para a verdadeira prática, Deus e a criação.

A ciência tem como objetivo alcançar o conhecimento do criador através da criação e compreender a ordem que lhe é relativa. A prática se direciona para o caminho necessário que o homem deve percorrer para participar corretamente da ordem fixada entre criador e criatura. O Corão possui estas duas funções, guiar os homens no caminho do conhecimento e da salvação. Respectivamente, a felicidade ou beatitude que é associada à compreensão do texto sagrado possui um sentido imanente e também um transcendente, pois a compreensão da ciência que envolve a compreensão de Deus e da criação, quando associadas a uma prática também orientada pelo livro sagrado, guiam os homens na direção das condições suficientes, por meio das quais ele poderá alcançar uma felicidade permanente nesta vida, e garantir sua permanência como um estado permanente na vida futura.

Longe de amarrar um sentido ultimo da revelação ao papel de guia que o filósofo adquire nesta perspectiva, e a despeito do caráter objetivo do texto sagrado, que deve valer igualmente para todos os homens; o verdadeiro sentido da revelação parece estar mesmo atrelado ao esforço individual em alcançá-lo. Ainda que o filósofo funcione como um guia, cabe a cada um formar para si sua própria compreensão do assentimento. Isso vai, propositalmente, distanciá-lo da posição dos "teólogos", de que a salvação dos

\footnotetext{
${ }^{27}$ TAYLOR, 2000, pg. 11.
} 
homens está atrelada a seu papel mediador, ou seja, que a salvação, ou a passagem de um estado de ignorância para o de sabedoria está atrelado ao teólogo, e não ao esforço individual. Estes supostos homens santos e milagrosos são grandes pecadores aos olhos de Averróis, pois impediram muitos homens de assentir corretamente, e não contemplam as múltiplas vias de assentimento garantidas por Deus, limitando-as a uma via única, determinada por eles. ${ }^{28}$

\section{Considerações finais}

Dizemos, então: tendo em conta que o propósito da Lei religiosa é o ensino da ciência verdadeira e da prática verdadeira e que tal ensino é de duas espécies: da representação e do assentimento como foi ressaltada pelos lógicos (ahl al-ilmbil-kalam); e que os métodos do assentimento para os homens são três: o demonstrativo, o dialético e o retórico; e que os métodos de produção da representação são dois: representação da coisa em si, ou de seu similar: tendo em conta que nem todos os homens, por sua natureza, dispõem-se a aceitar demonstrações- e mesmo argumentos dialéticos, e menos ainda argumentos demonstrativos! Além da dificuldade de aprendizagem dos argumentos demonstrativos e o longo tempo que se requer da parte daqueles que são aptospara tanto; e que o propósito da Lei é o de ensinar todos os homens, era preciso necessariamente que a Lei abrangesse todos os tipos de método de produção da representação. ${ }^{29}$

A interpretação aparece no trabalho intelectual de Averróis por diversas vezes e sob vários modos, embora o mais conhecido seja o que aparece no discurso decisivo. Pelo que se pode observar a partir da passagem supracitada, o contexto onde parece se formar o aparente "conflito" que esta obra procura dirimir, reside na tentativa de fazer prevalecer certa forma interpretativa que não é pautada por uma investigação demonstrativamente orientada.

No entanto, a revelação não pode estar submetida a impedimentos de ordem contextual, pois isto comprometeria exatamente o caráter "gratuito" de seu conteúdo. O alcance do texto revelado não pode se limitar ao número dos homens que possuam as condições necessárias para tanto, pois a revelação não pode ser atrelada a uma

\footnotetext{
${ }^{28}$ AVERRÓIS, 1996, pg. 165.

${ }^{29}$ AVERRÓIS, 1996, pg. 153.
} 
condicional que determine o seu sentido, uma vez que esta condicional é uma propriedade lógica que lhe será atribuída por um homem, cujo conhecimento da revelação, ainda que este seja um grande praticante da ciência demonstrativa, é limitado à sua condição composta, o que pode estabelecer um limite perigoso enquanto tenta fornecer a via, "por excelência", por meio da qual se deve ler a escritura.

Neste sentido, é necessário que o discurso relativo à revelação possua formas mais amplas de assentimento, que não se restrinja apenas aos indivíduos que possuem as competências relativas a filosofia, mas que alcance mesmo os homens que não conhecem sequer a tradição de leitura do texto sagrado. O recurso a interpretação adquire uma dimensão pedagógica, fundamental para que certos homens possam adquirir certo conhecimento da revelação ainda rudimentar, mas que já fornece as condições necessárias para que este indivíduo possa assentir corretamente.

A divisão das classes de assentimento em retórico, dialético e demonstrativo tem papel assertivo neste uso do discurso metafórico. Pois cada um destes níveis, além fornecerem vias válidas ao assentimento, também estabelecem o grau demonstrativo em que se encontra a convicção daquele que assente. Também é importante considerar a distância que existe entre o que pode ser chamado de um registro interpretativo, daquele de natureza demonstrativa, pois esta última não se configura exatamente como uma modalidade interpretativa, mas sim em uma tentativa de resposta pautada na busca pela verdade do que está sendo interpretado. Sua mensagem é a que mais se aproxima do verdadeiro que há na revelação, sendo também a modalidade que mais exclui a possibilidade de ambigüidade, pois não se relaciona com o âmbito daquilo que é provável, ao contrário, o objetivo da demonstração é alcançar a certeza que não pode ser manifesta de outro modo. ${ }^{30}$

A natureza das respostas fornecidas por cada uma das modalidades discursivas será a tônica classificatória de cada uma delas. As duas primeiras, por não possuírem uma natureza inferencial tão excludente quanto à demonstração, não se mostram capazes de resolver questões do mesmo modo que esta. A demonstração será capaz de

\footnotetext{
${ }^{30}$ Cf. BELO, 2012, pg. 91.
} 
fornecer a justificativa que conduz verdadeiramente ao assentimento religioso, ao passo que, as demais modalidades, conduzem apenas a certa opção determinada de assentimento, que está atrelado a essas modalidades, e depende muito mais de adesão, do que em uma compreensão da suposta verdade manifesta pelo argumento.

O problema reside no critério de justificação, tanto no que tange aos argumentos dialéticos quanto os retóricos, onde é possível identificar que exatamente o critério de justificação permanece externo ao próprio enunciado que está em análise. Neste sentido, ambos se distanciam em larga escala do argumento demonstrativo, cujo critério de justificação é exatamente a causa de sua adesão e fica evidente a partir do próprio argumento.

O ponto em questão diz respeito ao efeito que tais argumentos vêm a causar na alma dos indivíduos, ou ainda, ao grau de "certeza" que conduze me que será distinto em cada um dos casos. Isso se deve exatamente a relação direta que se estabelece entre o "grau de certeza" a que o enunciado de cada caso conduz, e o "critério de justificação" fornecido por ele. Assim, a precisão dos argumentos, no sentido do assentimento que geram, diz respeito ao grau de "externalidade" que há na relação entre a certeza e a justificação que devem se associar no assentimento. Por isso, a demonstração é o discurso mais apto a isso, sendo onde certeza e justificação estão essencialmente atreladas, uma é advinda da outra. Além disso, o caráter provável que se obtém a partir da "certeza" de um argumento retórico ou dialético sempre deixará em aberto a possibilidade para que o assentimento ocorra de outro modo. É possível observar, a partir disso, certa inversão na relação entre as três modalidades argumentativas admitidas por Averróis como válidas ao assentimento.

Primeiramente, é necessário considerar que o assentimento provocado por um argumento retórico demanda uma adesão prévia para que a "verdade" de seu conteúdo seja confirmada. Em outras palavras, a justificativa do assentimento só advém após a "certeza" de sua validade, que constitui um movimento precedente a este, onde o individuo "aceita" algo como "certo" e, apenas posteriormente, adquire condições para justificar seu assentimento. Por isso Averróis considera estes modos de adesão um tanto 
quanto frágeis em sua estrutura, pois representam um perigo, tanto para que assente por meio destes argumentos, quanto para quem acredita se instruir verdadeiramente por meio deles. $\mathrm{O}$ argumento demonstrativo constitui a forma correta de assentimento, visto que não depende da adesão para confirmar sua validade. Independente da vontade do indivíduo, um conteúdo de natureza demonstrativa impõe sua validade através de sua própria estrutura. O que não torna natural o assentimento, pois continua dependendo da preparação prévia do indivíduo para a compreensão de seu conteúdo.

Parece-nos que o problema de Averróis está na manutenção dos expedientes dialético e retórico como formas válidas de assentimento, visto que a demonstração, embora considerada sua forma por excelência, não é o único acesso a ela, sendo também uma via restrita a poucos homens privilegiados. Assim, é necessário que outras vias de assentimento se mostrem disponíveis aos homens.

Mas, se dialética e retórica são meios válidos para o acesso a escritura, como não relativizar o acesso a interpretação do texto sagrado? Como manter a unidade da mensagem divina diante da possibilidade de múltiplas vias de acesso? Parece-nos que a saída de Averróis está na compreensão desta separação como um expediente didático. Os dogmas da religião não estão submetidos à retórica ou a dialética, mas apenas associados a elas, na medida em que o conhecimento estiver associado a alegorias e imagens. Isto representa também uma etapa fundamental da compreensão de algo antes que se alcance o silogismo que representa o conhecimento propriamente dito.

Esta perspectiva se funda no estabelecimento do discurso demonstrativo como o modo "por excelência" de acesso ao texto revelado. Se esta é a investigação que expressa o que pode ser dito como sendo a "realidade" do texto sagrado, ao passo que as demais modalidades apenas "arranham" sua superfície, o método a ser aplicado deve considerar que apenas os indivíduos que possuam condições de acesso a ciência demonstrativa tem a autoridade para utilizar as demais modalidades para interpretar a mensagem. As características próprias dos argumentos dialéticos e retóricos se assentam no fato de que sua estrutura acaba por subtrair um significado real da escritura, em nome de uma leitura aproximada de seu sentido verdadeiro, o que resultaria na 
corrupção deste sentido e em um erro interpretativo. No entanto, a demonstração se aproxima de um sentido real do texto sagrado, e sua linguagem permite ao estudioso usar a dialética e a retórica para "acrescentar" interpretações complementares que são, obviamente, inferiores em sua verdade e precisão, mas que podem ser subalternamente acrescentadas na interpretação precisa do texto como elementos didáticos. O sentido real não é subtraído por este uso, que adquire uma dimensão auxiliar, simbólica, que não corrompe a leitura.

Averróis insiste na posição do filósofo como o legítimo guia dos homens simples é um tanto quanto forte, pois, no limite, o assentimento pela via retórica implicará quase que diretamente, no uso das paixões humanas para conduzir algum tipo de deliberação. Neste sentido, a relação do assentimento com a verdade contida no discurso daquele que tenta promovê-lo permanece retida em certa ambiguidade por parte de quem é o alvo de quem manifesta este discurso. Apenas aqueles homens que desenvolveram a ciência demonstrativa conhecem a lei sagrada o suficiente para que seu uso retórico conduza a um assentimento de acordo com aquilo que a escritura manifesta verdadeiramente. 
Número XXI - Volume III - dezembro de 2018 eticaefilosofia.ufjf.emnuvens.com.br

ISSN: $1414-3917$

e-ISSN: 2448-2137

\section{BIBLIOGRAFIA:}

Al-KINDI. A Filosofia Primeira. Trad. Miguel Attie Filho. São Paulo: Attie Produções Ltda, 2014.

AVERROES. Averroës' three short commentaries on Aristotle's "Topics," "Rhetoric, " and "Poetics". Tradução de Charles E. Butterworth. Albany : State University of New York Press, 1977.

Discours Decisif. Trad.: Marc Geoffroy. Paris, GF Flammarion, 1996.

L'Islam et la Raison. Trad.: Marc Geoffroy. Paris, GF Flammarion, 2000.

BAFFIONI, C. "Filosofia e religione"; in Islãm. Roma, La Nuova Italia Scientifica, 1997.

BELO, C. "Philosophical and Religious/Theological Knowledge in Averroes and Aquinas."; In: Existence, Cause, Essence. Essays in Islamic philosophy and Theology. Lisboa, Centro de Filosofia da Universidade de Lisboa, 2012.

BUTTERWORTH, C. Averroes: Politics and Opinion. The American Political Science Review, Vol. 66, No. 3 (Sep., 1972), pp. 894-901

GUERRERO, R.R. Obras filosóficas de Al-Kindi. Madrid, Editorial Coloquio, 1986.

HOURANI, G. F. “Averroes on Good and Evil”. Studia Islamica, 1962, (16), 13 - 40.

On the harmony of religion and philosophy a translation [from the Arabic], with introduction and notes, of Ibn Rushd's 'Kitab fasl al-maqal', with its appendix (Damima) and an extract from 'Kitab al-kashf 'an manahij al-adilla'. London, Gibb Memorial Trust, 2012.

KEMAL, S. The Philosophical Poetics of Alfarabi, Avicenna and Averroes. New York: Routledge, 2003.

LEAMAN, O. Ibn Rushd on Happiness and Philosophy. Studia Islamica, No. 52 (1980), pp. 167-181

MAHDI, M. Remarks on Averros Decisive Treatise. In: Islamic Theology and Philosophy, Studies in honour of G. F. Hourani. Albany, State University of New York Press, 1984, pg.188-203.

OZCOIDI, I. M. La Concepción de la Filosofiaen Averroes/AnálisisCrítico del Tahafut al-Tahafut. Madrid, Editorial Trotta. 2001. 
Número XXI - Volume III - dezembro de 2018 eticaefilosofia.ufjf.emnuvens.com.br

ISSN: $1414-3917$

e-ISSN: 2448-2137

TAYLOR, R. “Truth does not Contradict Truth: Averroes and the Unity of Truth.”, In: Topoi, 19.1. 2000, pg. 03-16.

"Averroes on the Sharî'ah of the Philosophers." In: The Muslim, Christian, and Jewish Heritage: Philosophical and Theological Perspectives in the Abrahamic Traditions. Richard C. Taylor \& Irfan Omar, eds. (Marquette University Press, Milwaukee, 2012), 283-304.

URVOY, D. Averroes, Las ambiciones de um intelectual musulmán. Madrid, Alianza Editorial, 1998. 